Article

\title{
A DFT Study of Acetylene Hydrogenation Catalyzed by $\mathrm{S}$-Doped $\mathrm{Pd}_{1} / \mathrm{g}-\mathrm{C}_{3} \mathrm{~N}_{4}$
}

\author{
Lihua Kang ${ }^{1, *}$, Mingyuan Zhu ${ }^{2}$ and Yu Zhao ${ }^{2}$ \\ 1 College of Chemistry \& Chemical Engineering, Yantai University, Yantai 264005, China \\ 2 College of Chemistry \& Chemical Engineering, Shihezi University, Shihezi 832000, China; \\ zhuminyuan@shzu.edu.cn (M.Z.); zhaoyu_0528@163.com (Y.Z.) \\ * Correspondence: lhkang@ytu.edu.cn; Tel.: +86-0993-2057213; Fax: +86-0993-2057270
}

Received: 25 September 2019; Accepted: 21 October 2019; Published: 25 October 2019

check for updates

\begin{abstract}
To exploit the excellent properties of $\mathrm{g}-\mathrm{C}_{3} \mathrm{~N}_{4}$, more and more studies have been carried out in various fields in recent years to improve the selectivity of catalysts, especially for selective acetylene hydrogenation. To our best knowledge, Pd catalyst is of great importance to hydrogenate acetylene in ethylene feed. Though we have explored the hydrogenation of acetylene catalyzed by $\mathrm{Pd}_{1} / \mathrm{g}-\mathrm{C}_{3} \mathrm{~N}_{4}$ before, doping with non-metals has never been studied. In this work, the mechanisms of selective hydrogenation of acetylene to ethylene on S-doped $\mathrm{Pd}_{1} / \mathrm{g}-\mathrm{C}_{3} \mathrm{~N}_{4}$ were investigated and we also compared this result with undoped $\mathrm{Pd}_{1} / \mathrm{g}-\mathrm{C}_{3} \mathrm{~N}_{4}$. By comparing the activation energy and selectivity of undoped $\mathrm{Pd}_{1} / \mathrm{g}-\mathrm{C}_{3} \mathrm{~N}_{4}$ with those of S-doped C and $\mathrm{N}$ sites of $\mathrm{Pd}_{1} / \mathrm{g}-\mathrm{C}_{3} \mathrm{~N}_{4}$, we found that S-doped $\mathrm{C}$ sites can improve the reactivity, but with a poor selectivity, while the activity of $\mathrm{S}$ atom doped $\mathrm{N}$ sites was not improved, but the selectivity has improved. Our work provides significant insights to explore the development of high efficiency non-metallic doping single metal atoms supported on 2D layered materials.
\end{abstract}

Keywords: S-doped $\mathrm{Pd}_{1} / \mathrm{g}-\mathrm{C}_{3} \mathrm{~N}_{4}$; activation; selectivity; acetylene hydrogenation

\section{Introduction}

Graphite carbonitride $\left(\mathrm{g}-\mathrm{C}_{3} \mathrm{~N}_{4}\right)$ is a planar two-dimensional lamellar structure similar to graphene, which is a candidate material that combines the merits of high surface area and low cost with the most stable phase of all allotropes under varied environmental conditions [1-4]. The preparation of g$\mathrm{C}_{3} \mathrm{~N}_{4}$ is relatively simple and inexpensive owing to the fact it can be obtained by urea pyrolysis [5] or direct heating of melamine [6], therefore people have become more interested in the study of $g-C_{3} \mathrm{~N}_{4}$. Since Wang et al. [7] first reported that g- $\mathrm{C}_{3} \mathrm{~N}_{4}$ can be used to generate hydrogen from water by using visible light photon energy, there has been increasing interest in the application of $g-\mathrm{C}_{3} \mathrm{~N}_{4}$ in different fields for its high chemical and thermal stability, low band gap energy [8] and a lot of efforts have been made to develop and further explore catalysts with excellent performance.

In order to improve the performance of $\mathrm{g}-\mathrm{C}_{3} \mathrm{~N}_{4}$, recent studies have proposed the strategy that g- $\mathrm{C}_{3} \mathrm{~N}_{4}$ also can be used as an excellent substrate for supporting catalysts to anchor single metal atoms and catalyze various reactions due to its more specific $\mathrm{N}$ species and larger $\mathrm{N}$ coordination cavity [9-11]. In 2015, Vilé and colleagues [12] investigated and studied a stable single catalyst that could anchor $\mathrm{Pd}$ atoms in the cavities of $\mathrm{g}-\mathrm{C}_{3} \mathrm{~N}_{4}$ while it could not anchor stably on $\mathrm{Al}_{2} \mathrm{O}_{3}$ supports, and it seems that active site isolation reduces the formation of high hydrocarbons (green oils) and improves the selectivity of catalysts, as also demonstrated for other types of reactions [13-15]. Motivated by these observations, Gao et al. [16] first studied the reduction of carbon dioxide by $\mathrm{Pd} / \mathrm{g}-\mathrm{C}_{3} \mathrm{~N}_{4}$ as photocatalyst through density functional theory, which showed that the photocatalysts exhibit excellent activity in $\mathrm{CO}_{2}$ reduction. In addition to photocatalysis, recent experiments have also used this strategy in other 
types of reactions, especially in selective acetylene hydrogenation to improve the catalyst selectivity. To our best knowledge, $\mathrm{Pd}$ catalysts are of great importance to hydrogenate acetylene in ethylene feed and the single-atom $\mathrm{Pd}_{1} / \mathrm{C}_{3} \mathrm{~N}_{4}$ catalyst exhibited higher ethylene selectivity compared with $\mathrm{Pd}$ clusters $[17,18]$. For example, $\mathrm{Lu}$ et al. [19] proved that single $\mathrm{Pd}$ atom supported on $\mathrm{C}_{3} \mathrm{~N}_{4}$-catalyzed acetylene hydrogenation exhibited excellent selectivity compared with Pd clusters and other support, and our previous study [20] also verified this experimental result well by using density functional theory calculation.

Previous experimental studies have shown that doping $\mathrm{C}_{3} \mathrm{~N}_{4}$ with various non-metallic elements [21-28] and heteroatoms [29-31] are effective ways to improve the photocatalytic performance, and in particular doping with $S$ heteroatoms has attracted more and more attention [25,32]. Xie et al. [33] used experimental and theoretical methods to study the advantages of S-doped $\mathrm{C}_{3} \mathrm{~N}_{4}$ nanosheets in surface morphology, special surface area and photocatalytic activity, and explained that the enhancement of photocatalytic activity could be attributed to coupling of the nanostructure and sulfuring. Based on DFT calculations, Wang et al. [34] presented a comprehensive study of $\mathrm{CO}_{2}$ reduction reaction on g- $\mathrm{C}_{3} \mathrm{~N}_{4}$ and S-doped $\mathrm{g}-\mathrm{C}_{3} \mathrm{~N}_{4}$ and made a conclusion that the photoactivity was enhanced by $\mathrm{S}$ doping. Sun et al. [35] prepared the Ni/g-S- $\mathrm{C}_{3} \mathrm{~N}_{4}$ composite photocatalyst and exhibited the best photocatalytic activity of $\mathrm{H}_{2}$ evolution from water under visible light irradiation. Inspired by these experiments, despite the excellent photocatalytic effect of S-doped $\mathrm{C}_{3} \mathrm{~N}_{4}$ on monoatomic metal catalysts and the fact $\mathrm{Pd}$-based catalysts are the best catalysts for acetylene hydrogenation, no experimental or theoretical studies have been carried out to explore acetylene hydrogenation reaction over $P d_{1} / S-g-C_{3} N_{4}$ catalysts so far. Therefore, in this work, we systematically investigate the $\mathrm{Pd}_{1} / \mathrm{S}-\mathrm{g}-\mathrm{C}_{3} \mathrm{~N}_{4}$ catalyzed hydrogenation of acetylene by using density functional theory.

Owing to the fact many experimental studies have shown that heteroatom doped $g-C_{3} N_{4}$ has two kinds of doping sites, namely C-doped sites and N-doped sites [36-38], therefore we constructed and found the optimal structure of S-doped $\mathrm{C}$ and $\mathrm{N}$ sites firstly, then we found the optimal adsorption sites of $\mathrm{C}_{2} \mathrm{H}_{2}$ and $\mathrm{H}_{2}$ molecules on the catalyst and obtained the co-adsorption structure, after that we began to study the whole reaction mechanism of acetylene hydrogenation catalyzed by these two dope sites after adsorbing a Pd atom, and compared the activity and selectivity with the catalyst undoped with $S$ atoms. Meanwhile, our work will provide significant insights to explore the development of high efficiency non-metallic doped single metal atom catalysts supported on 2D layered materials.

\section{Results and Discussion}

\subsection{Optimized S-Doped $g-C_{3} N_{4}$}

The optimized structures of g- $\mathrm{C}_{3} \mathrm{~N}_{4}$ and S-doped g- $\mathrm{C}_{3} \mathrm{~N}_{4}$, as well as the top and side view are shown in Figure 1. For S-doped g- $\mathrm{C}_{3} \mathrm{~N}_{4}$, there exist two doping sites, namely S-doped $\mathrm{C}$ sites and S-doped $\mathrm{N}$ sites. As shown in Figure 1a, there exist four doping sites for each doping mode, namely C1-C4 and N1-N4. In order to obtain the optimal doping structure, we examined these four different doping sites separately and obtained the optimal $\mathrm{C}$ and $\mathrm{N}$ doping sites. We can see that in Figure $1 \mathrm{c}$, gray corresponds to $\mathrm{C}$ atom, blue corresponds to $\mathrm{N}$ atom and yellow corresponds to $\mathrm{S}$ atom. From the side view, it can be seen that the structure of $\mathrm{g}-\mathrm{C}_{3} \mathrm{~N}_{4}$ is changed after S-doping $\mathrm{C}$ site, which is from wavy structure to bowl-shaped structure, while S-doping $\mathrm{N}$ site does not change its structure. 


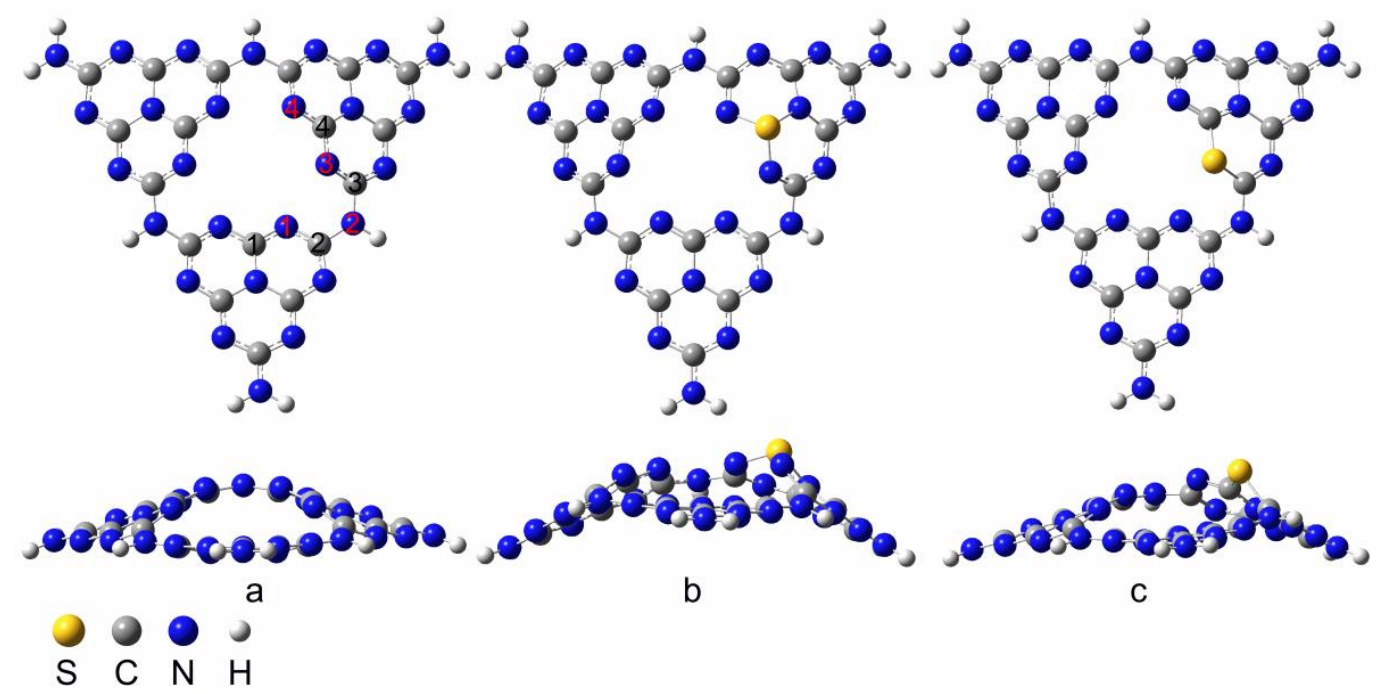

Figure 1. Top and side views of the most stable configurations of $g-\mathrm{C}_{3} \mathrm{~N}_{4}(\mathbf{a})$ and S-doped $g-\mathrm{C}_{3} \mathrm{~N}_{4}(\mathbf{b}, \mathbf{c})$.

Subsequently, in order to obtain the lowest energy configuration, we placed a single $\mathrm{Pd}$ atom at all possible sites and obtained the optimal adsorption sites. The optimal adsorption configuration of $\mathrm{Pd}$ adsorbed at the S-doped C site and N site can be seen in Figure 2a,b. The Pd atoms in the S-doped C site and the $\mathrm{N}$ site are all bonded to the $\mathrm{S}$ atom, with Pd-S bond lengths $2.29 \AA$ and $2.38 \AA$, respectively. In order to explore the optimal adsorption structure of the reactants, we analyzed the highest occupied orbital of the catalyst, which corresponds to the highest occupied molecular orbital (HOMO) pattern shown in Figure 2c,d. We found that the electron distribution of the highest occupied molecular orbitals produced by the two doping sites is concentrated on the Pd and S atoms, indicating that near the two atoms is the most likely site for adsorption. The HOMO energies were $-0.19727 \mathrm{eV}$ and $-0.1446 \mathrm{eV}$ respectively. For S-doped g- $\mathrm{C}_{3} \mathrm{~N}_{4}$ at $\mathrm{C}$ site, the Mulliken charge for $\mathrm{Pd}$ and $\mathrm{S}$ atoms are about $0.18 \mathrm{e}$ and $0.70 \mathrm{e}$, the adjacent two $\mathrm{N}$ atoms have a Mulliken charge of $-0.66 \mathrm{e}$ and $-0.51 \mathrm{e}$, while for S-doped g- $\mathrm{C}_{3} \mathrm{~N}_{4}$ at a $\mathrm{N}$ site, the Mulliken charge for Pd and $\mathrm{S}$ atoms are about 0.02e and 0.04e, with the adjacent two $\mathrm{N}$ atoms of $-0.40 \mathrm{e}$ and $-0.47 \mathrm{e}$, respectively. Both of these imply an electron transfer from $\mathrm{Pd}$ and $\mathrm{S}$ atoms to the $\mathrm{g}-\mathrm{C}_{3} \mathrm{~N}_{4}$ support, and there exists a strong interaction. Beside, when compared with previous studies [20], the corresponding electrons of the Pd atom decrease a lot after S-doping g- $\mathrm{C}_{3} \mathrm{~N}_{4}$ at a $\mathrm{C}$ site, indicating that $\mathrm{Pd}$ atom transfers more electrons to the support, while the electrons on $\mathrm{Pd}$ atoms do not change much for S-doped g- $\mathrm{C}_{3} \mathrm{~N}_{4}$ at a $\mathrm{N}$ site, which affects the activity of the reaction. 


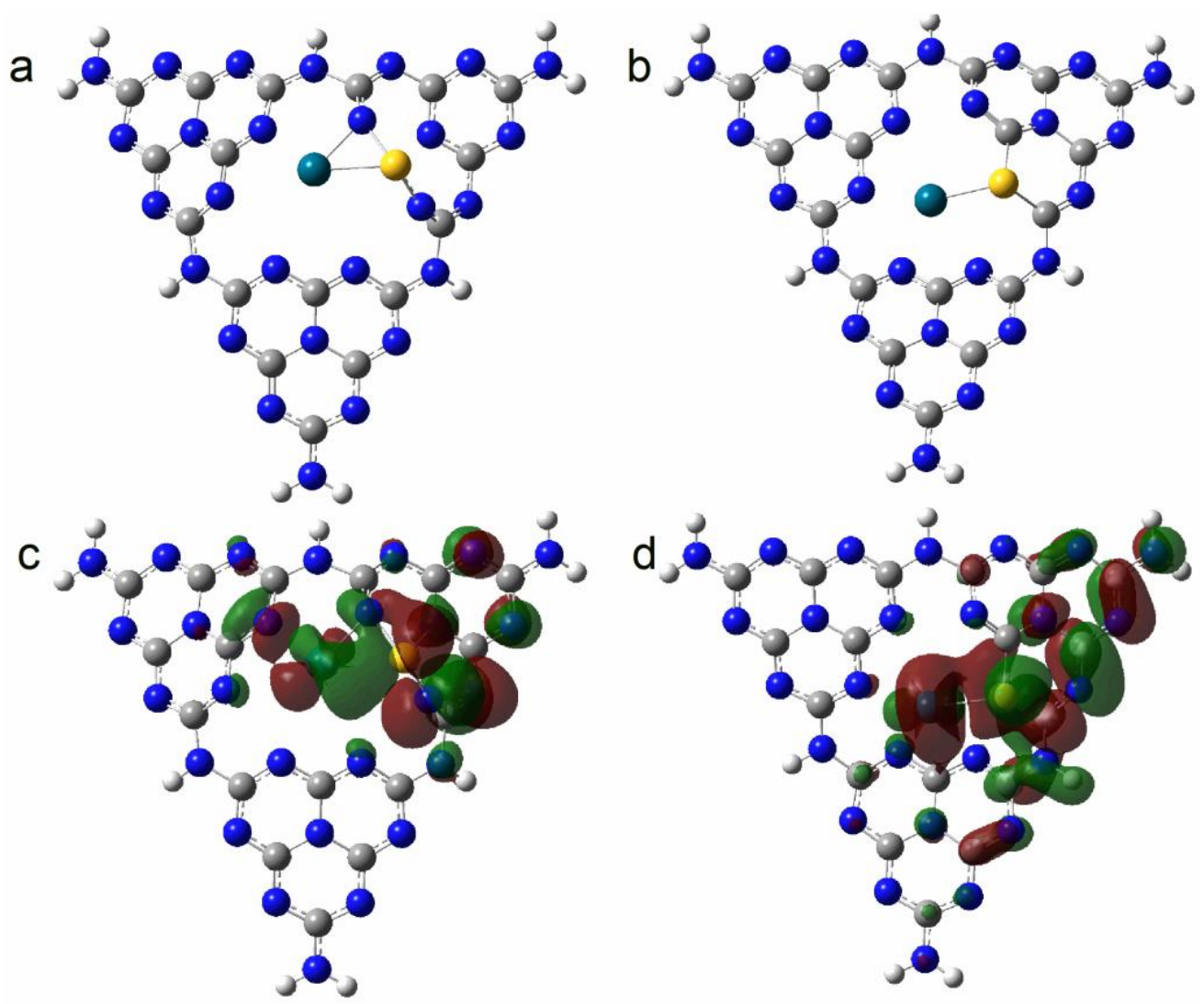

Figure 2. Optimal adsorption structure of $\mathrm{Pd}$ atoms on S-doped $\mathrm{g}-\mathrm{C}_{3} \mathrm{~N}_{4}$ and their corresponding highest occupied orbital.

\subsection{Adsorption of Reactants}

The reactants include $\mathrm{C}_{2} \mathrm{H}_{2}$ and $\mathrm{H}_{2}$ molecules, according to the highest occupied orbital from Figure $2 \mathrm{c}, \mathrm{d}$, molecular orbitals obtained by overlapping the same phase have the property of accumulating electrons in the region between atoms, thus forming stable bonds between atoms and forming molecular bonding orbitals, and it is found that the reactant is most likely to adsorb near $\mathrm{Pd}$ and $\mathrm{S}$ atoms. Therefore, we placed the reactants at different sites near the $\mathrm{S}$ and $\mathrm{Pd}$ atoms, such as the top and side of the Pd atom, the bridge of $S$ and $P d$ atom. By calculating the adsorption energy at different sites, we obtained the optimal adsorption structure. Figure 3a-d represent the optimal adsorption configurations of the doped $\mathrm{C}$ sites and the doped $\mathrm{N}$ sites, respectively. For the $\mathrm{S}$-doped $\mathrm{C}$ sites, both the optimal adsorption sites for the $\mathrm{C}_{2} \mathrm{H}_{2}$ and $\mathrm{H}_{2}$ molecules are on one side of the Pd atom, where the C-Pd bond length in the $\mathrm{C}_{2} \mathrm{H}_{2}$ adsorption structure is $2.18 \AA$, and the $\mathrm{C}-\mathrm{C}$ bond length is increased from $1.205 \AA$ to $1.236 \AA$, the bond angle of $\mathrm{C}_{2} \mathrm{H}_{2}$ also changed, with the adsorption energy of $-17.0 \mathrm{kcal} / \mathrm{mol}$. the $\mathrm{H}-\mathrm{Pd}$ bond length in $\mathrm{H}_{2}$ adsorption structure was $1.83 \AA$, and the $\mathrm{H}-\mathrm{H}$ bond length was also increased from $0.74 \AA$ to $0.79 \AA$, the adsorption energy was $-6.19 \mathrm{kcal} / \mathrm{mol}$. For the S-doped $\mathrm{N}$ sites, the optimal adsorption sites for the $\mathrm{C}_{2} \mathrm{H}_{2}$ and $\mathrm{H}_{2}$ molecules are at the top of the Pd atom, but the position of the $\mathrm{Pd}$ atom changes to the left $\mathrm{N}$ atom in the six-fold cavity, which is consistent with the results reported previously [13]. The C-C bond length in the $\mathrm{C}_{2} \mathrm{H}_{2}$ adsorption structure increases from $1.205 \AA$ to $1.261 \AA$, the C-Pd bond length is $2.06 \AA$, the bond angle also changes from $180^{\circ}$ to $155.5^{\circ}$, with the adsorption energy of $-21.62 \mathrm{kcal} / \mathrm{mol}$. The bond length in the $\mathrm{H}_{2}$ adsorption structure changes from $0.74 \AA$ to $0.87 \AA$, the H-Pd bond length is $1.67 \AA$, and the adsorption energy is $-8.16 \mathrm{kcal} / \mathrm{mol}$. We found that both the adsorption energy of the $\mathrm{C}_{2} \mathrm{H}_{2}$ molecules corresponding to these two different S-doping sites is larger than that of the $\mathrm{H}_{2}$ molecule, indicating that the $\mathrm{C}_{2} \mathrm{H}_{2}$ molecule preferentially adsorbs with respect to the $\mathrm{H}_{2}$ molecule, we also found that the adsorption energy of S-doped $\mathrm{N}$ atom for the reactant is larger than that of S-doped $\mathrm{C}$ atom for the reactant. Therefore after determining the 
preferential adsorption order of the reactants, we placed $\mathrm{H}_{2}$ molecules at different positions near the $\mathrm{C}_{2} \mathrm{H}_{2}$ molecule and obtained the most stable co-adsorbed structure. The structure can be seen in the following figure, then we start to explore the reaction mechanism of two different doping sites in detail.

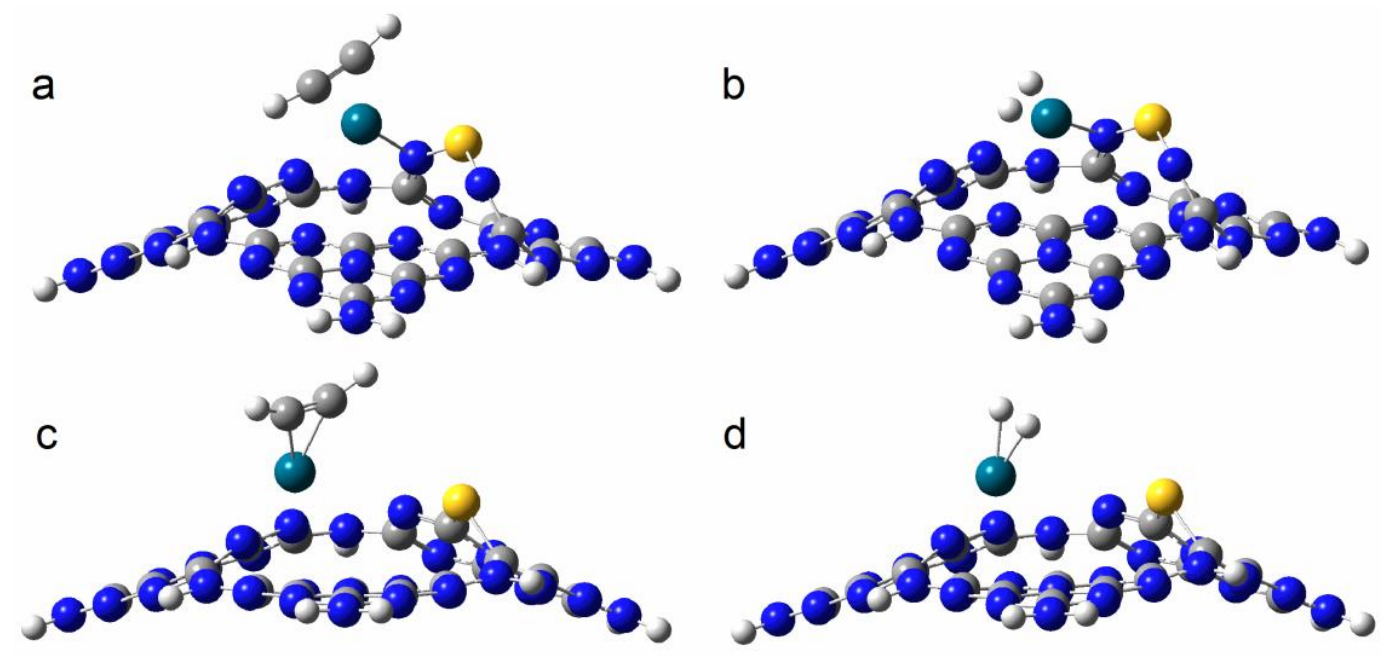

Figure 3. $(\mathbf{a}, \mathbf{b})$ and $(\mathbf{c}, \mathbf{d})$ represent the optimum adsorption configurations of acetylene and hydrogen on $\mathrm{S}$ doped $\mathrm{Pd}_{1} / \mathrm{C}_{3} \mathrm{~N}_{4}$ at $\mathrm{C}$ and $\mathrm{N}$ sites respectively.

\subsection{Reaction Mechanism of Acetylene Hydrogenation Catalyzed by S-Doped C Site}

The structure and energy corresponding to each step in the catalytic acetylene hydrogenation reaction at the S-doped C site can be seen in Figures 4 and 5, respectively. Hydrogenation has many side reactions, but we found that the process of continuous hydrogenation of acetylene is the optimal route based on our previous study, therefore we only study the reaction process and mechanism of this route. The hydrogenation process of this route is still divided into two steps, the first step is to hydrogenate acetylene to form the target product ethylene, and the second step to continue hydrogenation to produce by-product ethane.

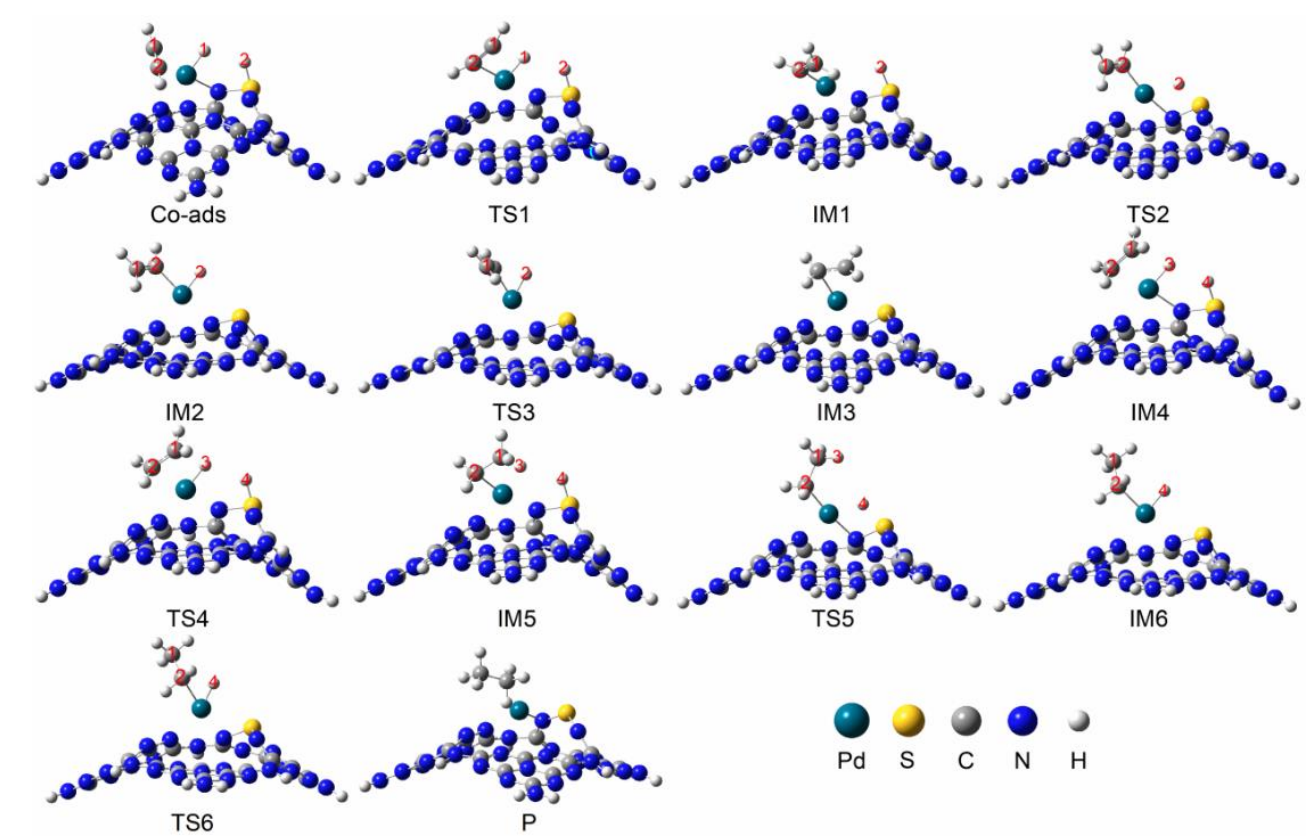

Figure 4. The reaction mechanism of acetylene hydrogenation catalyzed by S-doped C site and their corresponding structures. 

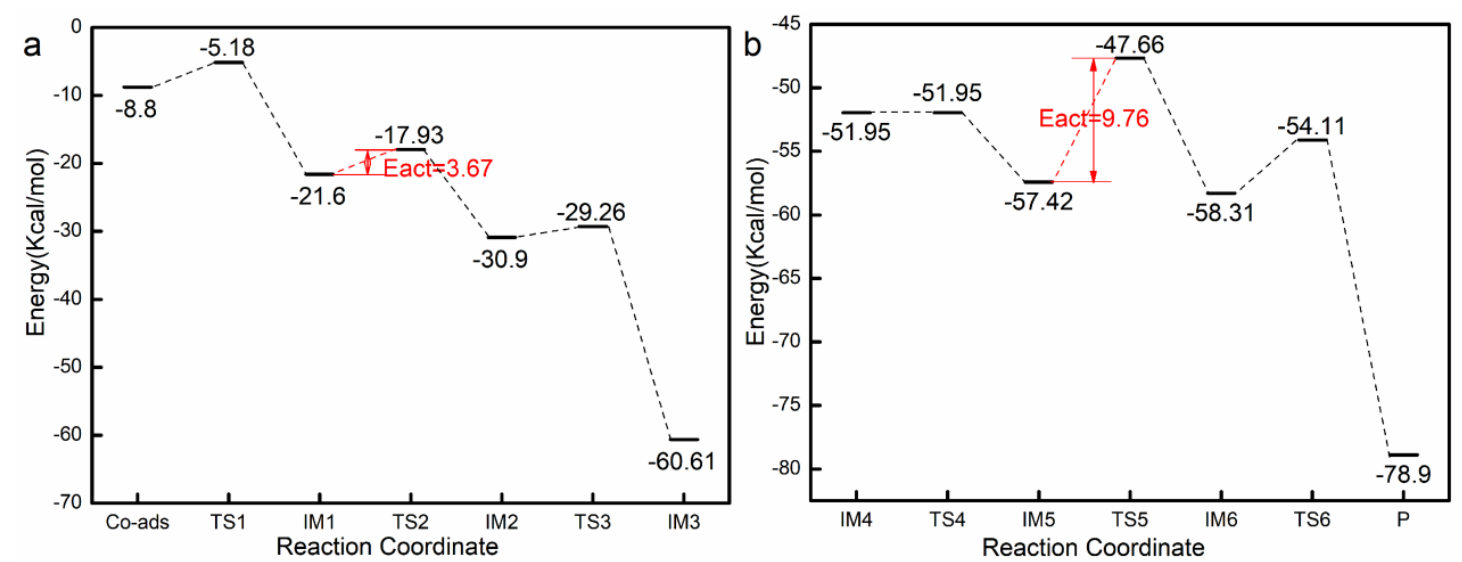

Figure 5. The energy diagrams of acetylene hydrogenation catalyzed by S-doped C site.

First, we studied the reaction process of hydrogenation of acetylene to ethylene. The catalytic hydrogenation reaction of this process is still started from the co-adsorption structure, we can see the co-ads structure in Figure 4. When we place the $\mathrm{H}_{2}$ molecule on the side of the $\mathrm{C}_{2} \mathrm{H}_{2}$ molecule, $\mathrm{H}_{2}$ molecules dissociate directly while bonding with $\mathrm{Pd}$ atoms and $\mathrm{S}$ atoms, with bond lengths of $1.52 \AA$ and $1.35 \AA$, respectively, which indicates that the $S$ atom doping promotes the dissociation process of $\mathrm{H}_{2}$ molecules, and then the sequential hydrogenation of the acetylene is started. The H1 atom will pass through the transition state TS1 and only needs to overcome an energy barrier of $3.62 \mathrm{kcal} / \mathrm{mol}$ to form the intermediate IM1. In the transition state TS1, the $\mathrm{H} 1$ atom is close to the $\mathrm{C} 1 \mathrm{atom}$, and its bond length is shortened from the co-adsorbed of $2.48 \AA$ to $1.80 \AA$. The atom of $\mathrm{H} 1$ vibrates in the direction of producing intermediate IM1. The transition state has only one imaginary frequency of $-30.58 \mathrm{~cm}^{-1}$. In the intermediate IM1, the $\mathrm{H} 1$ atom is connected to the $\mathrm{C} 1$ atom, and the bond length is shortened to $1.09 \AA$ A Since the $\mathrm{H} 2$ atom is far from the $\mathrm{C} 2$ atom, the $\mathrm{H} 2$ atom will generate ethylene (IM3) through two transition states (TS2, TS3). In the transition state TS2, the $\mathrm{H} 2$ atom is separated from the $\mathrm{S}$ atom, and the bond length is increased from $1.37 \AA$ to $1.65 \AA$. The vibration direction of the $\mathrm{H} 2$ atom is toward the $\mathrm{C} 2$ atom, with the only one virtual frequency of $-309.41 \mathrm{~cm}^{-1}$ and the activation energy is $3.67 \mathrm{kcal} / \mathrm{mol}$, which is the rate control step for the ethylene reaction process. In the intermediate IM2, the $\mathrm{H} 2$ atom is bonded to the Pd atom, the bond length is shortened from $1.84 \AA$ to $1.54 \AA$ in the transition state TS2, and the angle of C2-Pd-H2 is also reduced from $102.78^{\circ}$ to $77.79^{\circ}$. Then the intermediate IM2 will pass through a smaller energy barrier of $1.64 \mathrm{kcal} / \mathrm{mol}$ to form ethylene (IM3) via the transition state TS3. In the transition state TS3, the C2-H2 bond length shortened from $2.25 \AA$ to $1.67 \AA$, and the $\mathrm{H} 2$ atom vibrates to the $\mathrm{C} 2$ atom, and with only one virtual frequency of $-636.56 \mathrm{~cm}^{-1}$.

In all of the transition states found above, we also use IRC calculations to ensure that the transition state corresponds to the correct previous step reactant and the latter step intermediate to ensure the accuracy of the transition state. In IM3, H2 and C2 are bonded to each other to form an ethylene structure, and the desorption energy is $16.82 \mathrm{kcal} / \mathrm{mol}$, which is consistent with the absolute value of the adsorption energy of ethylene.

After the formation of ethylene, we explored the reaction process of ethylene hydrogenation to ethane. Similarly, a $\mathrm{H}_{2}$ molecule was placed at different positions near the $\mathrm{C}_{2} \mathrm{H}_{2}$ molecule and the optimal and most stable adsorption configuration was obtained, which was consistent with the co-adsorption structure obtained by the first acetylene hydrogenation. When ethylene is hydrogenated, the $\mathrm{H}_{2}$ molecule is also directly dissociated into two $\mathrm{H}$ atoms, which bond to $\mathrm{Pd}$ and $\mathrm{S}$ atoms, with the bond lengths of $1.53 \AA$ and $1.35 \AA$, respectively. Owing to the fact the $\mathrm{H} 3$ atom is very close to the $\mathrm{C} 1$ atom, we have found that the adsorbed structure did not need to overcome any energy barrier to form the intermediate IM5. In the transition state TS4, the H3 atom vibrates toward the C1 atom and the bond length is shortened to $1.77 \AA$, with only one imaginary frequency of $-263.15 \mathrm{~cm}^{-1}$. In the intermediate IM5, H3 atom associated with the $\mathrm{C} 1$ atom. Since the $\mathrm{H} 4$ atom attached to the $\mathrm{S}$ atom was 
far from the $\mathrm{C} 2$ atom, the $\mathrm{H} 4$ atom needs to undergo two transition states (TS5, TS6) to form the final product ethane (P). In the transition states TS5 and TS6, the $\mathrm{H} 4$ atom vibrate to the $\mathrm{C} 2$ atom, and the virtual frequencies were $-372.69 \mathrm{~cm}^{-1}$ and $-703.98 \mathrm{~cm}^{-1}$, Then $\mathrm{H} 4$ atom bonds with the $\mathrm{C} 2$ atom to form ethane.

During the whole second step of ethylene hydrogenation to ethane, each transition state was calculated by IRC to ensure that each transition state connect to the reactant in front and the intermediate in back. We found that the structure of carrier $\mathrm{g}-\mathrm{C}_{3} \mathrm{~N}_{4}$ in the two-step hydrogenation process (Co-ads and IM4 in Figure 4) was bowl-shaped, while that of carrier $g-C_{3} N_{4}$ in all transition states and intermediates in the reaction process was wavy. In addition, when we observe the structure of the target product ethylene (IM3) and the product ethane (P), the carrier structure of $\mathrm{g}-\mathrm{C}_{3} \mathrm{~N}_{4}$ was restored to the bowl shape, and such structural changes indicate that the catalyst plays a large role in the overall reaction.

\subsection{Reaction Mechanism of Acetylene Hydrogenation Catalyzed by S-Doped N Site}

Figures 6 and 7 illustrate the corresponding structures and energies in the catalytic acetylene hydrogenation reaction at the S-doped $\mathrm{N}$ site. We only introduce the mechanism of this optimal reaction path for continuous hydrogenation of acetylene. The first hydrogenation starts from co-ads (Co-ads), the co-adsorption energy is $-20.68 \mathrm{kcal} / \mathrm{mol}$, and the $\mathrm{C}_{2} \mathrm{H}_{2}$ and $\mathrm{H}_{2}$ molecules were adsorbed on both sides of the Pd atom, respectively. The bond length of the $\mathrm{H}_{2}$ molecule is only increased by $0.04 \AA$, indicating the $\mathrm{H}_{2}$ molecule is not activated. It can be seen from the figure that the co-adsorbed structure needs to generate the intermediate IM1 overcoming an energy barrier of $22.74 \mathrm{kcal} / \mathrm{mol}$. In the transition state (TS1), the $\mathrm{H} 1$ atom vibrates to the $\mathrm{C} 1 \mathrm{atom}$, and only one virtual frequency of $-753.54 \mathrm{~cm}^{-1}$ was generated. The distance between the $\mathrm{H} 1$ atom and the $\mathrm{H} 2$ atom became longer, indicating that the $\mathrm{H}_{2}$ molecule has been activated. In the intermediate IM1, $\mathrm{H} 1$ bonded to $\mathrm{C} 1$ atom, with the bond length shortened from $1.50 \AA$ to $1.17 \AA$. Owing to the fact the $\mathrm{H} 2$ atom is far from the C2 atom, the intermediate needs to pass through two transition states (TS2 and TS3) and overcome an energy barrier of $6.25 \mathrm{kcal} / \mathrm{mol}$ and $2.18 \mathrm{kcal} / \mathrm{mol}$ to produce ethylene (IM3). In the transition state TS2, the $\mathrm{C} 2$ atom vibrates toward the upper right while the $\mathrm{C} 2$ atom also vibrates in the direction of $\mathrm{H} 2$, with the virtual frequency of $-734.61 \mathrm{~cm}^{-1}$, and the bond angle of $\mathrm{C} 2-\mathrm{Pd}-\mathrm{H} 2$ is reduced from $161.81^{\circ}$ to $150.79^{\circ}$. In the structure of intermediate IM2, the bond length of Pd-C2 was reduced from $1.76 \AA$ to $1.54 \AA$, and the $\mathrm{C} 2-\mathrm{H} 2$ bond length was shortened from $3.60 \AA$ to $2.27 \AA$. The $\mathrm{H} 2$ atom in the transition state TS3 vibrates in the direction of ethylene generation, the virtual frequency is $-682.65 \mathrm{~cm}^{-1}$, and the bond length between $\mathrm{C} 2$ and $\mathrm{H} 2$ is shortened to $1.65 \AA$. Ethylene has been formed in IM3, and the desorption energy is $23.11 \mathrm{kcal} / \mathrm{mol}$, in the process of hydrogenation of acetylene to ethylene, the hydrogenation intermediate IM1 is a rate controlling step.

After the formation of ethylene, we continued to study the process of hydrogenation of ethylene to ethane. Similarly, we placed $\mathrm{a}_{2}$ molecule at different locations near the ethylene and obtained the optimal co-adsorption structure (IM4). In the transition state TS4, H3 atom vibrated toward the $\mathrm{C} 1$ atom while $\mathrm{H} 4$ atom and $\mathrm{C} 2$ atom also vibrate toward each other, the virtual frequency was $-704.52 \mathrm{~cm}^{-1}$ and the energy barrier in this process was $38.8 \mathrm{kcal} / \mathrm{mol}$. In the intermediate IM5, the H3-C1 bond length was shortened from $1.13 \AA$ to $1.09 \AA$, and the bond angle of $\mathrm{C} 2-\mathrm{Pd}-\mathrm{H} 4$ was reduced from $139.79^{\circ}$ to $80.26^{\circ}$. Subsequently, the intermediate IM5 only needs to overcome an energy barrier of $5.99 \mathrm{kcal} / \mathrm{mol}$ to generate ethane. In the transition state TS5, the $\mathrm{H} 4$ atom vibrated to the $\mathrm{C} 2 \mathrm{atom}$, its bond length is shortened from $2.34 \AA$ to $1.65 \AA$, and here was only one virtual frequency of $-756.61 \mathrm{~cm}^{-1}$. In the product structure, the $\mathrm{H} 4$ atom bonded to the $\mathrm{C} 2$ atom to form an ethane molecule and separated from the single Pd atom. The structure of the carrier $\mathrm{g}-\mathrm{C}_{3} \mathrm{~N}_{4}$ changed and the fragment structure of the left is recessed. In the two-step hydrogenation reaction, each transition state was verified by IRC calculations, ensuring the correct reactants and intermediates and the accuracy of the calculations. 


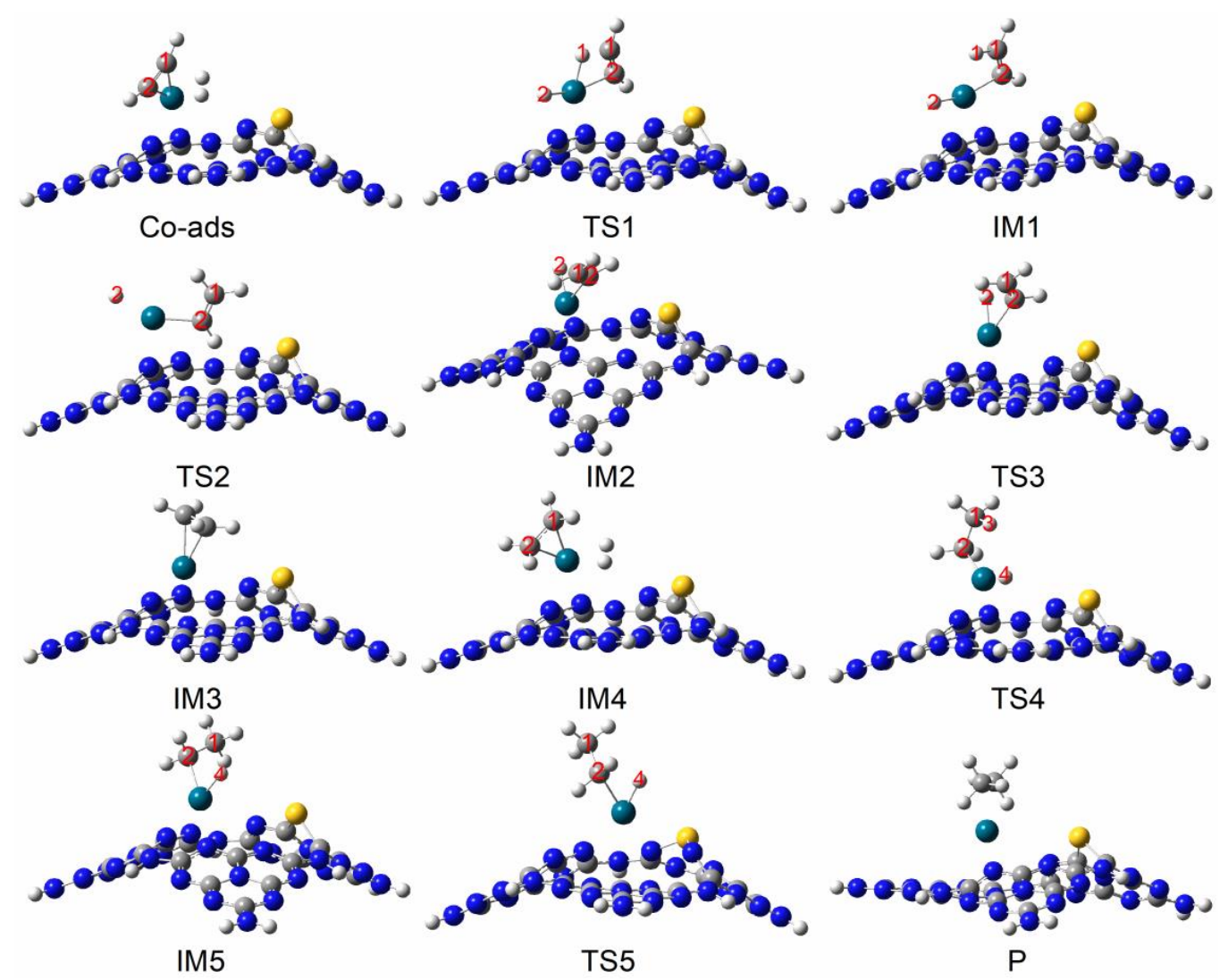

Figure 6. The reaction mechanism of acetylene hydrogenation catalyzed by S-doped N site and their corresponding structures.

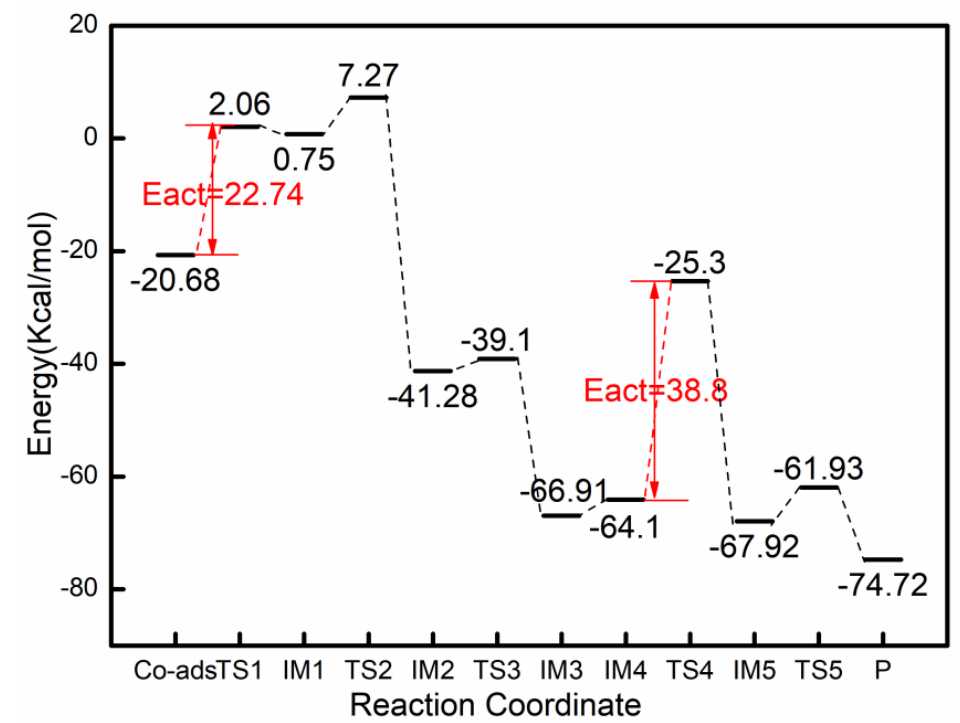

Figure 7. The energy diagrams of acetylene hydrogenation catalyzed by S-doped N site.

\subsection{Comparison of Activity and Selectivity before and after Doping S Atom}

First, we studied the corresponding change in activity after doping with $\mathrm{S}$ atoms. The activation energy of $\mathrm{Pd}_{1} / \mathrm{g}-\mathrm{C}_{3} \mathrm{~N}_{4}$ catalyzed hydrogenation of acetylene to ethylene with an undoped $\mathrm{S}$ catalyst was $21.53 \mathrm{kcal} / \mathrm{mol}$. For the S-doped C site, the activation energy of hydrogenation of acetylene to ethylene is $3.67 \mathrm{kcal} / \mathrm{mol}$, because the doping of $\mathrm{S}$ accelerates the dissociation of $\mathrm{H}_{2}$ molecules and results in a decrease in activation energy, while for S-doped $\mathrm{N}$ sites, the activation energy of hydrogenation of acetylene to ethylene is $22.74 \mathrm{kcal} / \mathrm{mol}$. The experimental results indicated that the doping of the $\mathrm{N}$ site 
does not increase the activation energy of the reaction, which is similar to the activation energy before undoping and S-doped $\mathrm{N}$ site had no effect on the activity of the reaction.

There are still two ways to judge the selectivity. The first is that the activation energy of ethylene hydrogenation to ethane is larger than that of acetylene hydrogenation to ethylene. Another is the difference between the activation energy of ethylene hydrogenation to ethane $\left(E_{a}\right)$ and the desorption energy of ethylene $\left(\left|\mathrm{E}_{\mathrm{ad}}\right|\right): \Delta \mathrm{E}=\mathrm{E}_{\mathrm{a}}-\left|\mathrm{E}_{\mathrm{ad}}\right|$, the larger difference represent the higher the selectivity of ethylene [39-41]. The activation energy of ethylene hydrogenation before $S$ doping is $38.88 \mathrm{kcal} / \mathrm{mol}$, which is larger than that of acetylene hydrogenation to ethylene $(21.53 \mathrm{kcal} / \mathrm{mol})$, and the selectivity is $15.4 \mathrm{kcal} / \mathrm{mol}$ according to the second method. For S-doped C atoms, the activation energy of ethylene hydrogenation to ethane is $9.76 \mathrm{kcal} / \mathrm{mol}$, which is larger than the activation energy of acetylene hydrogenation to ethylene $(3.67 \mathrm{kcal} / \mathrm{mol})$. For the first method, owing to the fact the desorption energy of ethylene $(16.82 \mathrm{kcal} / \mathrm{mol})$ is much larger than the activation energy of ethylene hydrogenation to ethane $(9.76 \mathrm{kcal} / \mathrm{mol})$, the selectivity is not high according to the selectivity judgment formula. For S-doped $\mathrm{N}$ sites, the activation energy $(38.8 \mathrm{kcal} / \mathrm{mol})$ of ethane formation in the second step is larger than that in the first step $(22.74 \mathrm{kcal} / \mathrm{mol})$, and the difference between the activation energy $(38.8 \mathrm{kcal} / \mathrm{mol})$ of ethane formation by-product and the desorption energy $(23.11 \mathrm{kcal} / \mathrm{mol})$ of ethylene is $15.69 \mathrm{kcal} / \mathrm{mol}$, which means the selectivity is $15.69 \mathrm{kcal} / \mathrm{mol}$ and slightly larger than that of ethylene production in the first step $(22.74 \mathrm{kcal} / \mathrm{mol})$.

\section{Computational Methods}

All the density functional theory (DFT) calculations were performed by using the Guassian09 software package [42]. In the process of geometrical optimizations, the nonlocal correlation functional of Lee, Yang and Parr (B3LYP) [43] with the 6-31G** basis were set for C, N, S, H atoms and the Los Alamos effective core pseudo-potentials (ECP) basis set LANL2DZ was applied to the Pd atoms. The energies of all structures presented in the whole reaction pathway were zero-point (ZPE) energy corrections at the same level of optimization and there are no geometric constraints during the structural optimization processes. In order to verify that the optimized structure has the lowest energy with no imaginary frequency or the transition structure with only one imaginary frequency, we calculate the harmonic vibration frequency at the same theoretical level. In addition, intrinsic reaction coordinate (IRC) $[44,45]$ calculations were executed to ensure that each transition state links the correct reactant and product during reaction process. We also calculated adsorption energy $\left(E_{a d s}\right)$ and co-adsorption energy $\left(\mathrm{E}_{\mathrm{co}-\text {-ads }}\right)$ during the study, which were defined as follows:

$$
\begin{gathered}
\mathrm{E}_{\text {ads }}=\mathrm{E}_{\text {ads-state }}-\left(\mathrm{E}_{\mathrm{C}_{2} \mathrm{H}_{2} / \mathrm{H}_{2}}+\mathrm{E}_{\mathrm{Pd} / \mathrm{S}-\mathrm{C}_{3} \mathrm{~N}_{4}}\right) \\
\mathrm{E}_{\text {co-ads }}=\mathrm{E}_{\text {co-ads-state }}-\left(\mathrm{E}_{\mathrm{C}_{2} \mathrm{H}_{2}}+\mathrm{E}_{\mathrm{H}_{2}}+\mathrm{E}_{\mathrm{Pd} / \mathrm{S}-\mathrm{C}_{3} \mathrm{~N}_{4}}\right)
\end{gathered}
$$

In the above two formulas, $\mathrm{E}_{\mathrm{ads}-\text { state }}$ and $\mathrm{E}_{\mathrm{co}-\text { ads-state }}$ are the whole energy of the reactant and

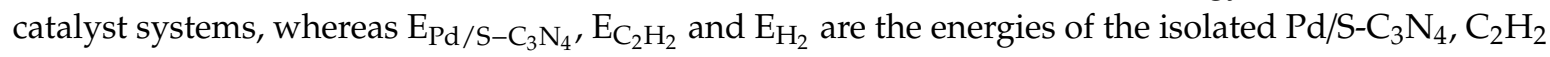
or $\mathrm{H}_{2}$ molecules.

\section{Conclusions}

In this study, we have carried out density functional calculations to investigate the mechanism of selective acetylene hydrogenation reactions over S-doped g- $\mathrm{C}_{3} \mathrm{~N}_{4}$. Firstly, we found that after doping with $S$ atoms, the overall structure of $\mathrm{g}-\mathrm{C}_{3} \mathrm{~N}_{4}$ corresponding to the $\mathrm{C}$-doping site is bowl-shaped, while that of $\mathrm{g}-\mathrm{C}_{3} \mathrm{~N}_{4}$ corresponding to the $\mathrm{N}$-doping site is wavy-shaped, and the monoatomic Pd is still adsorbed in the six-fold cavity of g- $\mathrm{C}_{3} \mathrm{~N}_{4}$. Then for S-doped $\mathrm{C}$ sites, the optimal sites for $\mathrm{C}_{2} \mathrm{H}_{2}$ and $\mathrm{H}_{2}$ are on the side of the $\mathrm{Pd}$ atom, where the $\mathrm{C}_{2} \mathrm{H}_{2}$ adsorption energy is $-17.0 \mathrm{kcal} / \mathrm{mol}$ and $\mathrm{H}_{2}$ adsorption energy is $-6.19 \mathrm{kcal} / \mathrm{mol}$. For $\mathrm{S}$-doped $\mathrm{N}$ sites, the optimal adsorption sites of $\mathrm{C}_{2} \mathrm{H}_{2}$ and $\mathrm{H}_{2}$ molecules are at the top of the Pd atom, but the position of the Pd atom was changed to the upper left of $\mathrm{N}$ atoms in the six-fold cavity. The adsorption energy of $\mathrm{C}_{2} \mathrm{H}_{2}$ is $-21.62 \mathrm{kcal} / \mathrm{mol}$ and that of $\mathrm{H}_{2}$ is $-8.16 \mathrm{kcal} / \mathrm{mol}$. 
The adsorption energy of $\mathrm{C}_{2} \mathrm{H}_{2}$ molecules corresponding to these two different S-doping sites is higher than that of $\mathrm{H}_{2}$ molecules, which indicates that $\mathrm{C}_{2} \mathrm{H}_{2}$ molecules have preferential adsorption over $\mathrm{H}_{2}$ molecules and the adsorption energy of S-doped $\mathrm{N}$ atom for reactants is higher than that of S-doped $\mathrm{C}$ atoms. Then, by comparing the activation energy and selectivity of undoped $\mathrm{S}$ atoms with those of $\mathrm{S}$-doped $\mathrm{C}$ and $\mathrm{N}$ sites, we found that S-doped $\mathrm{C}$ sites can improve the reactivity owing to the S-doped $\mathrm{C}$ site promote the dissociation of $\mathrm{H}_{2}$ molecules. However, ethylene is not easy to dissociate from the catalyst surface, resulting in poor selectivity, while the activity of $\mathrm{N}$ site doped with $\mathrm{S}$ atom is not improved, with a slightly improved for selectivity.

Author Contributions: L.K. and M.Z. designed experiments; L.K. and Y.Z. carried out experiments; M.Z. analyzed experimental results. L.K. and Y.Z. wrote the manuscript.

Funding: This research was funded by the National Natural Science Fundation of China (NSFC, Grant No. 21363020) and the Science and Technology Fund Projects of Shihezi University (No. 2014ZRKXJQ03).

Conflicts of Interest: We have no conflict of interests.

\section{References}

1. Zhang, Y.; Mori, T.; Ye, J. Polymeric Carbon Nitrides: Semiconducting Properties and Emerging Applications in Photocatalysis and Photoelectrochemical Energy Conversion. Sci. Adv. Mater. 2012, 4, 282-291. [CrossRef]

2. Yang, L.; May, P.W.; Yin, L.; Brown, R.C.D.; Scott, T.B. Direct Growth of Highly Organized Crystalline Carbon Nitride from Liquid-Phase Pulsed Laser Ablation. Chem. Mater. 2006, 18, 5058-5064. [CrossRef]

3. Cao, S.; Yu, J. g- $\mathrm{C}_{3} \mathrm{~N}_{4}$-Based Photocatalysts for Hydrogen Generation. J. Phys. Chem. Lett. 2014, 5, 2101-2107. [CrossRef]

4. Deifallah, M.; McMillan, P.F.; Corà, F. Electronic and Structural Properties of Two-Dimensional Carbon Nitride Graphenes. J. Phys. Chem. C 2008, 112, 5447-5453. [CrossRef]

5. Liu, J.; Zhang, T.; Wang, Z.; Dawson, G.; Chen, W. Simple pyrolysis of urea into graphitic carbon nitride with recyclable adsorption and photocatalytic activity. J. Mater. Chem. 2011, 21, 14398-14401. [CrossRef]

6. Yan, S.C.; Li, Z.S.; Zou, Z.G. Photodegradation Performance of g-C3N4 Fabricated by Directly Heating Melamine. Langimuir 2009, 25, 10397-10401. [CrossRef]

7. Maeda, K.; Wang, X.; Nishihara, Y.; Lu, D.; Antonietti, M.; Domen, K. Photocatalytic Activities of Graphitic Carbon Nitride Powder for Water Reduction and Oxidation under Visible Light. J. Phys. Chem. C 2009, 113, 4940-4947. [CrossRef]

8. Yin, H.; Guo, Q.; He, D.; Li, J.; Sun, S. Acid-induced crystallinity enhancement of graphite-like C3N3+xHy synthesized through a facile one-pot approach. Chem. Phys. Lett. 2017, 669, 22-28. [CrossRef]

9. Ma, X.; Lv, Y.; Xu, J.; Liu, Y.; Zhang, R.; Zhu, Y. A Strategy of Enhancing the Photoactivity of g- $\mathrm{C}_{3} \mathrm{~N}_{4}$ via Doping of Nonmetal Elements: A First-Principles Study. J. Phys. Chem. C 2012, 116, 23485-23493. [CrossRef]

10. Liu, A.Y.; Cohen, M.L. Prediction of New Low Compressibility Solids. Science 1989, 245, 841. [CrossRef]

11. Niu, C.; Lu, Y.Z.; Lieber, C.M. Experimental Realization of the Covalent Solid Carbon Nitride. Science 1993, 261, 334. [CrossRef]

12. Vilé, G.; Albani, D.; Nachtegaal, M.; Chen, Z.; Dontsova, D.; Antonietti, M.; López, N.; Pérez-Ramírez, J. A stable single-site palladium catalyst for hydrogenations. J. Angew. Chem. 2015, 54, 11265. [CrossRef]

13. Kumar, N.; Ghosh, P. Selectivity and Reactivity of Pd-Rich PdGa Surfaces toward Selective Hydrogenation of Acetylene: Interplay of Surface Roughness and Ensemble Effect. J. Phys. Chem. C 2016, 120, 28654-28663. [CrossRef]

14. Cao, Y.; Sui, Z.; Zhu, Y.; Zhou, X.; Chen, D. Selective Hydrogenation of Acetylene over Pd-In/Al2O3 Catalyst: Promotional Effect of Indium and Composition-Dependent Performance. ACS Catal. 2017, 7, 7835-7846. [CrossRef]

15. Albani, D.; Shahrokhi, M.; Chen, Z.; Mitchell, S.; Hauert, R.; López, N.; Pérez-Ramírez, J. Selective ensembles in supported palladium sulfide nanoparticles for alkyne semi-hydrogenation. J. Nat. Commun. 2018, 9, 2634. [CrossRef]

16. Gao, G.; Jiao, Y.; Waclawik, E.R.; Du, A. Single Atom (Pd/Pt) Supported on Graphitic Carbon Nitride as an Efficient Photocatalyst for Visible-Light Reduction of Carbon Dioxide. J. Am. Chem. Soc. 2016, 138, 6292-6297. [CrossRef] 
17. Lindlar, H. Ein neuer Katalysator für selektive Hydrierungen. Helv. Chim. Acta 1952, 35, 446-450. [CrossRef]

18. Yang, B.; Burch, R.; Hardacre, C.; Headdock, G.; Hu, P. Influence of surface structures, subsurface carbon and hydrogen, and surface alloying on the activity and selectivity of acetylene hydrogenation on Pd surfaces: A density functional theory study. J. Catal. 2013, 305, 264-276. [CrossRef]

19. Huang, X.; Xia, Y.; Cao, Y.; Zheng, X.; Pan, H.; Zhu, J.; Ma, C.; Wang, H.; Li, J.; You, R.; et al. Enhancing both selectivity and coking-resistance of a single-atom Pd1/C3N4 catalyst for acetylene hydrogenation. Nano Res. 2017, 10, 1302-1312. [CrossRef]

20. Zhao, Y.; Zhu, M.; Kang, L. The DFT Study of Single-Atom $\mathrm{Pd}_{1} / \mathrm{g}-\mathrm{C}_{3} \mathrm{~N}_{4}$ Catalyst for Selective Acetylene Hydrogenation Reaction. Catal. Lett. 2018, 148, 2992-3002. [CrossRef]

21. Chai, B.; Yan, J.; Wang, C.; Ren, Z.; Zhu, Y. Enhanced visible light photocatalytic degradation of Rhodamine B over phosphorus doped graphitic carbon nitride. Appl. Surf. Sci. 2017, 391, 376-383. [CrossRef]

22. Sagara, N.; Kamimura, S.; Tsubota, T.; Ohno, T. Photoelectrochemical $\mathrm{CO}_{2}$ reduction by a p-type boron-doped g- $\mathrm{C}_{3} \mathrm{~N}_{4}$ electrode under visible light. Appl. Catal. B Environ. 2016, 192, 193-198. [CrossRef]

23. Wang, K.; Li, Q.; Liu, B.; Cheng, B.; Ho, W.; Yu, J. Sulfur-doped g- $\mathrm{C}_{3} \mathrm{~N}_{4}$ with enhanced photocatalytic $\mathrm{CO}_{2}$-reduction performance. J. Appl. Catal. B Environ. 2015, 176-177, 44-52. [CrossRef]

24. Lan, D.-H.; Wang, H.-T.; Chen, L.; Au, C.-T.; Yin, S.-F. Phosphorous-modified bulk graphitic carbon nitride: Facile preparation and application as an acid-base bifunctional and efficient catalyst for $\mathrm{CO}_{2}$ cycloaddition with epoxides. Carbon 2016, 100, 81-89. [CrossRef]

25. Liu, G.; Niu, P.; Sun, C.; Smith, S.C.; Chen, Z.; Lu, G.Q.; Cheng, H.-M. Unique Electronic Structure Induced High Photoreactivity of Sulfur-Doped Graphitic $\mathrm{C}_{3} \mathrm{~N}_{4}$. J. Am. Chem. Soc. 2010, 132, 11642-11648. [CrossRef]

26. Dong, G.; Zhao, K.; Zhang, L. Carbon self-doping induced high electronic conductivity and photoreactivity of $\mathrm{g}^{-} \mathrm{C}_{3} \mathrm{~N}_{4}$. Chem. Commun. 2012, 48, 6178-6180. [CrossRef]

27. Huang, Z.-F.; Song, J.; Pan, L.; Wang, Z.; Zhang, X.; Zou, J.-J.; Mi, W.; Zhang, X.; Wang, L. Carbon nitride with simultaneous porous network and O-doping for efficient solar-energy-driven hydrogen evolution. Nano Energy 2015, 12, 646-656. [CrossRef]

28. Lu, C.; Chen, R.; Wu, X.; Fan, M.; Liu, Y.; Le, Z.; Jiang, S.; Song, S. Boron doped g- $\mathrm{C}_{3} \mathrm{~N}_{4}$ with enhanced photocatalytic $\mathrm{UO}_{2}{ }^{2+}$ reduction performance. Appl. Surf. Sci. 2016, 360, 1016-1022. [CrossRef]

29. Zhang, G.; Zhang, M.; Ye, X.; Qiu, X.; Lin, S.; Wang, X. Iodine Modified Carbon Nitride Semiconductors as Visible Light Photocatalysts for Hydrogen Evolution. Adv. Mater. 2014, 26, 805-809. [CrossRef]

30. Lan, Z.-A.; Zhang, G.; Wang, X. A facile synthesis of Br-modified g- $\mathrm{C}_{3} \mathrm{~N}_{4}$ semiconductors for photoredox water splitting. Appl. Catal. B Environ. 2016, 192, 116-125. [CrossRef]

31. Zhang, Y.; Mori, T.; Ye, J.; Antonietti, M. Phosphorus-Doped Carbon Nitride Solid: Enhanced Electrical Conductivity and Photocurrent Generation. J. Am. Chem. Soc. 2010, 132, 6294-6295. [CrossRef] [PubMed]

32. Chen, J.; Hong, Z.; Chen, Y.; Lin, B.; Gao, B. One-step synthesis of sulfur-doped and nitrogen-deficient g- $\mathrm{C}_{3} \mathrm{~N}_{4}$ photocatalyst for enhanced hydrogen evolution under visible light. Mater. Lett. 2015, 145, 129-132. [CrossRef]

33. Xie, L.; Dai, Y.; Zhou, Y.; Chang, X.; Yin, L. Sulfur (VI) modified graphite carbon nitride nanosheets with chrysanthemum-like structure and enhanced photocatalytic activity. Chem. Phys. Lett. 2018, 693, 1-7. [CrossRef]

34. Wang, Y.; Tian, Y.; Yan, L.; Su, Z. DFT Study on Sulfur-Doped g- $\mathrm{C}_{3} \mathrm{~N}_{4}$ Nanosheets as a Photocatalyst for $\mathrm{CO}_{2}$ Reduction Reaction. J. Phys. Chem. C 2018, 122, 7712-7719. [CrossRef]

35. Sun, C.; Zhang, H.; Liu, H.; Zheng, X.; Zou, W.; Dong, L.; Qi, L. Enhanced activity of visible-light photocatalytic $\mathrm{H}_{2}$ evolution of sulfur-doped $\mathrm{g}-\mathrm{C}_{3} \mathrm{~N}_{4}$ photocatalyst via nanoparticle metal $\mathrm{Ni}$ as cocatalyst. Appl. Catal. $B$ Environ. 2018, 235, 66-74. [CrossRef]

36. Zhu, B.; Zhang, J.; Jiang, C.; Cheng, B.; Yu, J. First principle investigation of halogen-doped monolayer g-C3N4 photocatalyst. Appl. Catal. B Environ. 2017, 207, 27-34. [CrossRef]

37. He, Q.; Zhou, F.; Zhan, S.; Huang, N.; Tian, Y. Photoassisted oxygen reduction reaction on mpg-C3N4: The effects of elements doping on the performance of ORR. Appl. Surf. Sci. 2018, 430, 325-334. [CrossRef]

38. Jiang, L.; Yuan, X.; Pan, Y.; Liang, J.; Zeng, G.; Wu, Z.; Wang, H. Doping of graphitic carbon nitride for photocatalysis: A reveiw. Appl. Catal. B Environ. 2017, 217, 388-406. [CrossRef]

39. Yang, B.; Burch, R.; Hardacre, C.; Hu, P.; Hughes, P. Selective hydrogenation of acetylene over Cu(211), $\mathrm{Ag}(211)$ and $\mathrm{Au}(211)$ : Horiuti-Polanyi mechanism vs. non-Horiuti-Polanyi mechanism. Catal. Sci. Technol. 2017, 7, 1508-1514. [CrossRef] 
40. Yang, K.; Yang, B. Surface restructuring of Cu-based single-atom alloy catalysts under reaction conditions: The essential role of adsorbates. Phys. Chem. Chem. Phys. 2017, 19, 18010-18017. [CrossRef]

41. Yang, B.; Burch, R.; Hardacre, C.; Hu, P.; Hughes, P. Importance of surface carbide formation on the activity and selectivity of Pd surfaces in the selective hydrogenation of acetylene. Surf. Sci. 2016, 646, 45-49. [CrossRef]

42. Frisch, G.W.T.M.J.; Schlegel, H.B.; Scuseria, G.E.; Robb, M.A.; Cheeseman, J.R.; Scalmani, G.; Barone, V.; Mennucci, B.; Petersson, G.A.; Nakatsuji, H.; et al. Gaussian 09 Citation. Gaussian Inc.: Wallingford, CT, USA, 2010. Available online: https://gaussian.com/g09citation/ (accessed on 24 October 2019).

43. Lee, C.; Yang, W.; Parr, R.G. Development of the Colle-Salvetti correlation-energy formula into a functional of the electron density. Phys. Rev. B Condens. Matter. 1988, 37, 785-789. [CrossRef] [PubMed]

44. Gonzalez, C.; Schlegel, H.B. An improved algorithm for reaction path following. J. Chem. Phys. 1989, 90, 2154-2161. [CrossRef]

45. Gonzalez, C.; Schlegel, H.B. Reaction path following in mass-weighted internal coordinates. J. Phys. Chem. 1990, 94, 5523-5527. [CrossRef]

(C) 2019 by the authors. Licensee MDPI, Basel, Switzerland. This article is an open access article distributed under the terms and conditions of the Creative Commons Attribution (CC BY) license (http://creativecommons.org/licenses/by/4.0/). 